\title{
Does the generalist parasitic plant Cuscuta campestris selectively forage in heterogeneous plant communities?
}

\author{
Alexander M. Koch ${ }^{1,2}$, Christof Binder ${ }^{2}$ and Ian R. Sanders ${ }^{1}$ \\ Botanical Institute, Hebelstrasse 1, 4056 Basle, Switzerland; ${ }^{1}$ present address: Department of Ecology and Evolution, Biology Building, University of Lausanne, \\ 1015 Lausanne, Switzerland; ${ }^{2}$ These authors contributed equally to the work
}

Author for correspondence:

Ian R. Sanders

Tel: +41216924261

Fax: +41216924265

Email: lan.Sanders@ie-bsg.unil.ch

Received: 30 October 2003

Accepted: 11 November 2003

doi: 10.1111/j.1469-8137.2004.00999.x

\section{Summary}

- Cuscuta spp. are holoparasitic plants that can simultaneously parasitise several host plants. It has been suggested that Cuscuta has evolved a foraging strategy based on a positive relationship between preuptake investment and subsequent reward on different host species.

- Here, we establish reliable parasite size measures and show that parasitism on individuals of different host species alters the biomass of $C$. campestris, but that, within host species size and age, also contributes to the heterogeneous resource landscape.

- We then performed two additional experiments to test whether $C$. campestris achieves greater resource acquisition by parasitising two host species rather than one and, whether $C$. campestris forages in communities of hosts offering different rewards (a choice experiment).

- There was no evidence in either experiment for direct benefits of a mixed host diet. Cuscuta campestris foraged by parasitising the most rewarding hosts the fastest and then investing the most on them. We conclude that our data present strong evidence for foraging in the parasitic plant $C$. campestris.

Key words: Cuscuta, foraging, heterogeneity, parasitic plant, resource acquisition.

(c) New Phytologist (2004) 162: 147-155

\section{Introduction}

All organisms live in environments where resources are at least to some degree heterogeneously distributed either in space (Mack \& Harper, 1977) or time (Gibson, 1988; Venable et al., 1993). The process associated with searching for and consuming resources has been referred to as foraging, and this has been studied in detail theoretically as well as experimentally for many animals (Charnov, 1976; Krebs et al., 1977; Milinski $\&$ Heller, 1978). Clonal plants have been shown to exploit resource patches of different qualities by nonrandom ramet placement, and this has also been considered as foraging (Kelly, 1992; Evans \& Cain, 1995; Fischer \& Van Kleunen, 2002). Many species of parasitic plants have the ability to parasitise different host plant species in a community at the same time (Pennings \& Callaway, 2002). This generalist strategy allows the parasite to invade new areas and become established on host species with which they have not coevolved. Furthermore, preferences for certain hosts can lead to parasite induced changes in plant community structure and diversity (Pennings \& Callaway, 1996).

Species in the genus Cuscuta have been used to address questions concerning foraging by parasitic plants. Cuscuta seedlings produce stems that coil around host plants and build haustoria; structures that penetrate the host tissue and connect to the phloem and xylem of the host (Christensen et al., 2003). Once parasitism is established, the germination root of the young Cuscuta dies leaving no connection to the soil. A Cuscuta individual can parasitise many host individuals simultaneously by coiling about leaves and stems with its tendrillike shoots. Cuscuta growth can easily be observed because it grows entirely on the above-ground parts of its hosts. This offers a unique opportunity to investigate foraging patterns in a clonally integrated and parasitic plant in a detailed manner. Each host individual represents a distinct resource patch for the parasite on which it can form new attachment sites to access the hosts resources. The species used in this study, Cuscuta campestris, is holoparasitic and therefore completely 
dependent on its hosts' resources in order to grow and complete its life cycle (Dinelli et al., 1993).

It has been suggested that Cuscuta subinclusa optimally forages (Kelly, 1990) by a positive relationship between investment and reward. Kelly (1990) also proposed that Cuscuta exhibits a preuptake response that allows the parasite to discriminate among hosts and then invest the most on the best hosts. In these experiments, C. subinclusa formed initial coils of $c .15-35 \mathrm{~mm}$ on six plant species tested, but actually only showed any growth increase in the first $30 \mathrm{~d}$ on three of these hosts (Kelly, 1990). Consequently, we question the validity of the reported relationship between investment and reward, if these 'nonhosts' are removed from the analysis. Furthermore, several Cuscuta species exhibit a coiling response on nonliving or nonbiological material, from which it is unlikely that they receive any reward (the authors' personal observation).

The question of whether Cuscuta has evolved a foraging strategy to enhance its growth in a heterogeneous landscape depends on whether the hosts that it can parasitise within a community actually differ in their reward in a way that affects Cuscuta fitness. Kelly (1990) states that the six host species differ in their reward (measured as biomass accumulation per initial length of coil), although, again, the analysis of covariance was performed including the three 'nonhosts'. Thus, the significant host species effect could reflect the differing reward between hosts and nonhosts, rather than showing that host species differ in their rewards.

Several other factors can result in differences in host quality that are not dependent on the identity of the host species. Differences among populations, previous selection, local adaptation and genetic variation significantly influence the interaction between Cuscuta europaea and Urtica dioica (Koskela et al., 2000; Koskela et al., 2001; Koskela et al., 2002). One other factor that has received little attention is the effect of within-host species variation in age and size on Cuscuta growth. Therefore, many sources of variation can alter the parasites' fitness and, hence, the evolution of foraging patterns.

Simultaneous exploitation of complementary resource patches by clonally integrated plants can result in enhanced growth by the reallocation of resources through ramets (Stuefer et al., 1994; Hutchings \& Wijesinghe, 1997; Van Kleunen \& Stuefer, 1999). Therefore, Cuscuta could obtain a reward from parasitising a mixture of host species that is greater than that obtained from parasitising monocultures of the same host species. Kelly \& Horning (1999) found higher stem densities of $C$. attenuata in natural stands where two different host species co-occurred than in places of monocultures of the two hosts. In a transplant experiment, where C. attenuata was sequentially parasitising the two different hosts, overall stem volume was higher in case of a mixed diet. This did not, however, result in a significant effect in terms of d. wt increase.
The test for whether a generalist Cuscuta sp. forages requires that plant communities consist of hosts that differ in their rewards. The parasite should have an equal possibility of parasitising any of the hosts. To our knowledge, such experiments have not previously been carried out with parasitic plants.

In this study, we tested the hypothesis that parasitism in different patches alters the $\mathrm{d}$. wt of $C$. campestris, where individuals of different host species represent different resource patches. We tested a further hypothesis that host size and age contribute to the heterogeneous landscape. Because we found that the different host species altered d. wt accumulation of C. campestris, we carried out two further experiments. The first of these was to test whether $C$. campestris could increase its d. wt, carbon and nitrogen content from parasitising two different host species rather than parasitising two hosts of the same species. The second was to test whether $C$. campestris forages by parasitising the most beneficial hosts, or combinations of hosts that offer different rewards in communities where the parasite had equal opportunity to parasitise any of the hosts (a choice experimental design).

\section{Materials and Methods}

\section{Study species}

Native to North America, the parasitic plant Cuscuta campestris Y. has a wide host range and has spread over other continents. It can cause acute local problems and crop loss in agriculture (Parker \& Riches, 1993). In this study we used three host species: Daucus carota L. (Apiaceae), a biennial that forms only a vegetative rosette in its first growing season; Trifolium alexandrinum $\mathrm{L}$. and Trifolium resupinatum $\mathrm{L}$., which are both annuals belonging to the Fabaceae. All three species are described as hosts of C. campestris in Switzerland and have been observed growing together around field margins (Beuret, 1981). The seeds of the three host species were obtained from Fenaco (Winterthur, Switzerland). The seeds of C. campestris Y. were obtained from the botanical garden of Kiel (Germany) for experiments A and B. C. campestris seeds used in experiments $\mathrm{C}$ and $\mathrm{D}$ were randomly sampled from a natural population near Davies, CA (collected in August 1998 by T. Lanini, University of California, USA).

In a pilot experiment conducted in the summer of 1997 we grew single C. campestris individuals on individual plants of the three above described host species. At the start of flowering of C. campestris both C. campestris $\mathrm{d}$. wt and stem length were significantly correlated with the weight of reproductive parts of $C$. campestris ( $r=0.64, P \leq 0.01$ and $r=0.53, P \leq$ 0.05 , respectively). As plant size is often an important component of fitness and as in temperate zones $C$. campestris is an annual, this suggests therefore that the two size measurements $C$. campestris $\mathrm{d}$. wt and stem length are fitness related growth traits. 


\section{Experimental design and plant growth conditions}

Experiment A The aim of this experiment was to test whether the d. wt of $C$. campestris differed when it parasitised individual host plants of three different host species. Seeds of $D$. carota, T. alexandrinum and T. resupinatum were germinated in garden soil and 10 individuals of each host species were transplanted into pots $(10 \mathrm{~cm}$ diameter $\times 10.5 \mathrm{~cm}$ high $)$ when they reached the two-leaf stage. The substrate was a low nutrient sandy soil. The plants were grown in a glasshouse, regularly watered and fertilised weekly with $50 \mathrm{ml}, 0.5-$ strength Hoagland solution (Hoagland \& Arnon, 1950). Day length was a minimum of $16 \mathrm{~h}$, supplemented with artificial light when necessary. The temperature ranged between $18^{\circ} \mathrm{C}$ and $30^{\circ} \mathrm{C}$.

C. campestris seeds were stratified with sandpaper, surface sterilised (with $2 \%$ bleach, $15 \mathrm{~min}$ ), rinsed twice with sterile water and germinated on water agar plates (5\%). After $1 \mathrm{wk}$, the $C$. campestris seedlings were transplanted into pots that each contained one host plant. Each $C$. campestris individual was placed next to the stem of a host plant. The host plants were five weeks old at the time when $C$. campestris seedlings were placed next to the 10 individuals of each host species on 9 October, 1997. The position of the individual pots was randomised every $10 \mathrm{~d}$.

C. campestris seedlings undergo a lag phase after the initial coiling on a host, during which they form haustoria that penetrate the host tissue, before any resources are taken up. The stem length of each $C$. campestris individual was measured from the time of transplantation to the date when $C$. campestris stem length began to increase, to test whether the length of the lag phase differed between the host species.

In experiment $A$ and all other experiments, the size of the host plants was estimated at the time when $C$. campestris seedlings were placed next to the hosts. The number of leaves and the length of the longest leaf of each host individual were recorded. These variables were measured so that they could be used as a covariate to test whether any significant treatment differences were an effect of initial host size.

At harvest, after 88-92 d, each C. campestris individual was manually separated from its host, $C$. campestris stem length was recorded, and parasite tissue was removed for drying and weighing. Host shoot and host root tissues were separately dried and weighed after drying at $80^{\circ} \mathrm{C}$ for $2 \mathrm{~d}$. Experimental procedures in experiments $\mathrm{B}$ to $\mathrm{D}$ are the same as for experiment $A$, except where indicated.

Experiment B The aim of Experiment B was to test whether there is an effect of host size and age on the growth of $C$. campestris. Three cohorts of the host plant $T$. resupinatum were grown. The age-classes of host plants differed from each other by 3 wk. C. campestris was placed onto 26 individual hosts of each age-class at the same time when the cohorts were 3, 6 and 9 wk old. Four weeks following transplantation of
C. campestris on 17 February, 1998 all replicates were harvested. As the two factors age and size are inextricably linked, no attempt was made to separate them in this experiment.

The measurements in experiment B at harvest were host shoot and root d. wt and C. campestris $\mathrm{d}$. wt.

Experiment C In Experiment C, C. campestris individuals were allowed to grow on two host plants, D. carota and $T$. resupinatum (abbreviated as $\mathrm{D}$ and $\mathrm{R}$, respectively). These two hosts were chosen because $C$. campestris biomass had been previously shown to differ significantly according to which of these two hosts it parasitised (see Results of experiment A). The aim of the experiment was to investigate the parasites' resource uptake on the different hosts and to test whether $C$. campestris could acquire more resources (biomass, carbon and nitrogen content) by parasitising two different host species, rather than two hosts of the same species. C. campestris seedlings were transplanted when the hosts were $69 \mathrm{~d}$ old. When parasitism was successful on a first host, C. campestris was allowed to grow onto a second host of either the same or the other species. The second host was the same age as the first host and grown under exactly the same conditions. On the second host, parasitism lasted at least $11 \mathrm{~d}$ after the formation of the first attachment site. Each $C$. campestris individual growing on two hosts was considered as one replicate. The four treatments are abbreviated as DD, DR, RD, and RR, respectively, where the first letter represents the host on which parasitism was initiated and the second letter indicates the second host onto which $C$. campestris grew. Plants were kept in the same conditions as in experiment $A$, except that the plants were fertilised every $10 \mathrm{~d}$ with $12 \mathrm{ml}$ of 0.35 -strength Hoaglands solution and that the positions of the pairs of host plants were randomised.

When the first flower buds appeared on C. campestris $8 \mathrm{~d}$ before harvest, pulse labelling was carried out using $15 \mathrm{~N}$. The only modification of the fertiliser solution used for the labelling was that the nitrate comprised 98\% 15 N (Cambridge Isotope Laboratories, Andover, MA, USA) compared with the natural abundance of $0.037 \%$ present in the normal Hoaglands solution. In total, all plants received the same amount of nitrogen. Controls of each treatment were plants that received no label and these were used to estimate the background $15 \mathrm{~N}$ abundance. There were 10 replicate controls in each treatment except treatment $\mathrm{RD}$, where replicate number was nine. The number of replicates of labelled plants were: DD: 6, 5; DR: 11, 9; RD: 8, 9; RR: 4, 5, where the first and second host received label, respectively. At harvest, the number of attachment sites on the hosts that received label were counted. The C. campestris tissue and shoots of two hosts of each replicate were dried and weighed. By means of mass spectrometry analyses (ANCASL, MS 20-20, PDZ Europe, Crewe, UK), total nitrogen and carbon content, as well as $15 \mathrm{~N}$ label uptake (total $15 \mathrm{~N}-$ background $15 \mathrm{~N}$ ), of the host shoots and $C$. campestris were measured. C:N-ratio was calculated as carbon content 
divided by nitrogen content for each $C$. campestris individual. The experiment lasted for $11 \mathrm{wk}$ after the first transplantation of the parasite seedlings onto the host plants on 25 May, 1999.

Experiment D In experiment D, we tested whether $C$. campestris would enhance its growth by parasitising the most beneficial hosts, or host combinations, in communities of hosts offering different rewards and where the parasite had equal opportunity to parasitise any of the hosts. To do this, we set up 45 microcosms in plastic boxes $(30 \mathrm{~cm}$ long $\times 20 \mathrm{~cm}$ wide $\times 25 \mathrm{~cm}$ deep), each comprising 15 hosts. Each box was drained using a drainage mat at the bottom. Six different treatments were established, which differed in the composition of the host community: Monocultures of $D$. carota, T. alexandrinum, and $T$. resupinatum, two two-species communities, of which one species was $T$. resupinatum and the other was either $T$. alexandrinum or D. carota and communities with all three host species. We had five replicates of each monoculture and 10 initial replicates for each mixed-species treatment. The hosts were chosen for uniformity in size and a predetermined number of each host was planted. Hosts were planted in the boxes in a superimposed hexagonal grid arrangement so that the plants were equidistant to their neighbours at the time of planting. The position of each species within the grid was randomised. In the two-species treatments, seven and eight plants of each species were selected and this was determined randomly. In the three-species treatment, 5 hosts of each species were planted per box. After four weeks of growth, C. campestris seedlings were placed next to the central host individual. C. campestris individuals that died were replaced by new seedlings for $5 \mathrm{wk}$ after placing the first ones. 0.5 litre of 0.5-strength Hoaglands solution was applied to each box every $4 \mathrm{wk}$. The growth of each $C$. ampestris individual was recorded every $3 \mathrm{~d}$ by counting the number of attachment sites per host individual. In the treatments with two host species and three host species, the order in which $C$. campestris parasitised the hosts of each box was recorded. A host was only considered to be parasitised if $C$. campestris had formed at least three attachment sites. This was to avoid including random establishments where one parasite shoot often forms one or two attachment sites but never three (personal observation). The temperature ranged between $10^{\circ} / 25^{\circ}$ Celsius (night/day). The plants were harvested when $C$. campestris started to flower. The number of attachment sites per host individual and the total number of $C$. campestris shoots were recorded before C. campestris and host shoots were dried and weighed. The experiment was conducted for $37 \mathrm{wk}$ after the first transplantation of parasite seedlings on 16 June, 1999.

\section{Statistical analyses}

All correlations were calculated using unconstrained least square estimates. R-square values were adjusted for unequal sample sizes (Zar, 1984).
Variables measured in experiments A to D were analysed using ANOVA. Where indicated, differences between means of treatments were tested using least significant difference (LSD) (Zar, 1984). Where necessary, variables were transformed to meet the requirement of normal distribution before performing ANOvA. Bartlett's test was used to test for homoscedasticity of variance for each variable (Zar, 1984). The variables of host and $C$. campestris growth in experiment $A$ were analysed using one-way ANOVA with plant species as a fixed factor, with three levels. Initial host size (estimated as the product of the number of leaves and the length of the longest leaf for each host) was used as a covariate.

Variables in experiment B were analysed using one-way ANOVA with cohort as a fixed factor, with three levels. Variables in experiments $\mathrm{C}$ and $\mathrm{D}$ were analysed by ANOvA, with the fixed factor host species composition with 4 and 6 levels, respectively. Label capture in experiment $C$ was analysed with ANOVA with the fixed factor label treatment with six levels and ANCOVA, where the number of attachment sites on the labelled host was used as a covariate.

Attachment sites on a host are the places of resource uptake by $C$. campestris. After the formation of haustoria on a first host, $C$. campestris shoots explore the environment and will eventually parasitise new hosts. The sequence in which $C$. campestris parasitises the different hosts therefore provides a ranking system. This allowed us to test, in experiment D, whether $C$. campestris had foraged for the most beneficial hosts. This ranking procedure avoids confounding influences of the time it took $C$. campestris to parasitise the hosts in the different treatments. Under the null hypothesis of no $C$. campestris foraging, the mean ranks for the different host species of each box are expected to be equal. To test this hypothesis, we compared the rank sums of each host species in the mixed-species treatments using the nonparametric Wilkoxon test. For the three monoculture treatments, ANOVA was used to test whether there was any difference in the average number of attachments per host species at harvest. For each of the three mixed-species treatments paired $t$-tests were used to compare differences in the average number of attachment per host species.

\section{Results}

\section{Effects of different host species on C. campestris growth (experiment $\mathrm{A}$ )}

There was no significant difference in total host d. wt among the three host species at harvest (Fig. 1a). C. campestris d. wt, however, differed significantly according to which host species it was parasitising (Fig. 1b). C. campestris grew significantly larger on $T$. resupinatum than on $T$. alexandrinum and $D$. carota. Fitting the initial host size as a covariate did not qualitatively alter the host species effect on the weight of $C$. campestris. The weight of $C$. campestris per gram host shoot 
New

Phytologist

Fig. 1 Growth of Cuscuta campestris and host plants in experiment A. Total d. wt of parasitised hosts (a), C. campestris d. wt (b) and $C$. campestris $d$. wt per host shoot $d$. wt (c), at the final harvest. Bars represent + $1 \mathrm{SE}$. The letters D, A and R indicate the host species Daucus carota, Trifolium alexandrinum and $T$. resupinatum, respectively. Different letters above bars indicate a significant difference $(P \leq 0.05)$ according to the LSD test. $F$-ratios from the ANOVA of the host species effect for data shown in (a) (b) and (c) were; $F_{(2,27)}=0.70$ (ns), $F_{(2,27)}=3.39(P \leq 0.05)$ and $F_{(2,27)}=5.64(P \leq 0.01)$, respectively.

Fig. 2 Mean Cuscuta campestris d. wt (a), Trifolium resupinatum total host $\mathrm{d}$. wt (b) and C. campestris d. wt per T. resupinatum shoot d. wt (c) in experiment B. Host plants were three cohorts of different ages. F-ratios from the ANOVA of the host age effect for data shown in (a) (b) and (c) were $F_{2,59}=8.63$ $(P \leq 0.001), F_{2,59}=29.47(P \leq 0.001)$ and $F_{2,59}=2.40(P \leq 0.10)$, respectively. Bars represent $+1 \mathrm{SE}$. Different letters above bars indicate a significant difference $(P \leq 0.05)$ according to the LSD test. (a)

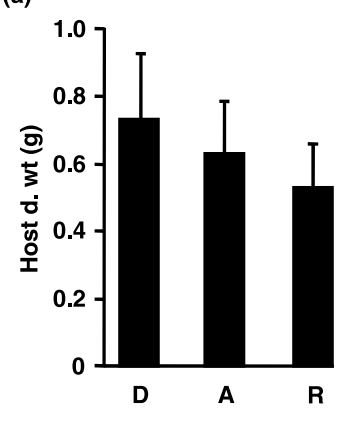

(b)

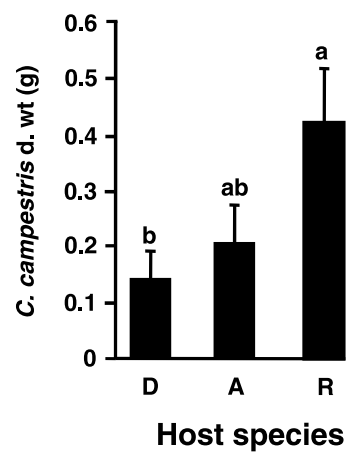

(c)

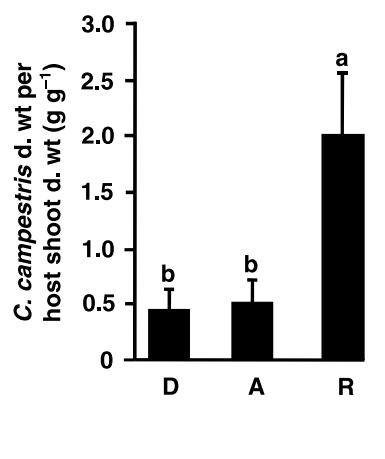

(a)

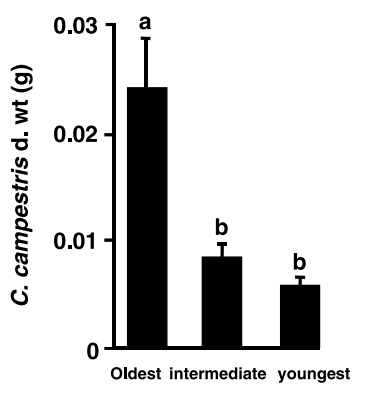

(b)

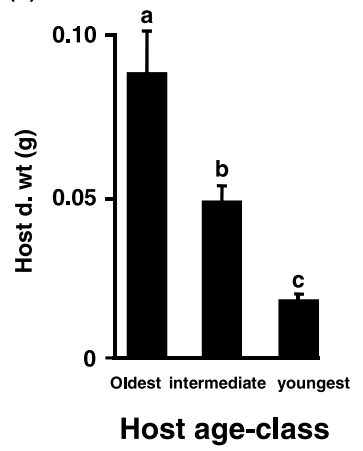

(c)

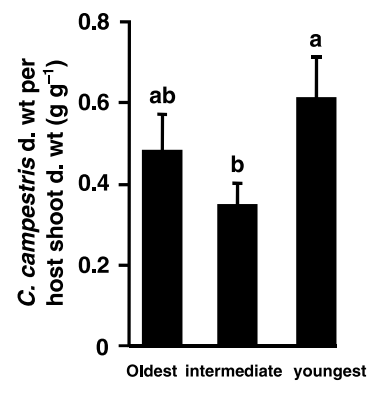

tissue also differed significantly among the different host treatments (Fig. 1c), indicating that the host species effect on $C$. campestris d. wt was also independent of host size. At harvest, $C$. campestris stem length was significantly correlated with $C$. campestris d. wt when all hosts were considered together $(r=0.96, P \leq 0.001)$. This was also the case for each host species separately $(r=0.98,0.94$ and 0.98 for $D$. carota, $T$. alexandrinum, and $T$. resupinatum, respectively; all $P \leq 0.001)$.

The length of the lag phase that occurred after germination, did not differ significantly for the three host species $(16.4 \pm 2.09,17.4 \pm 2.09$ and $16.0 \pm 2.48 \mathrm{~d} \pm \mathrm{SE}$ for $D$. carota, $T$. alexandrinum and $T$. resupinatum, respectively).

\section{Effects of host age and size on growth of $C$. campestris (experiment B)}

In experiment $\mathrm{B}$, the $\mathrm{d}$. wt of $C$. campestris was significantly affected by the age of the $T$. resupinatum host plants (Fig. 2a). C. campestris grew significantly larger on older hosts than on younger hosts. As expected, the total d. wt of the hosts also differed significantly among age-classes (Fig. 2b). Despite the size effects, $C$. campestris was able to exploit the younger hosts more efficiently, as shown by the marginally significant differences of the weight of $C$. campestris per gram host shoot tissue among age classes (Fig. 2c). C. campestris growing on the oldest hosts and the youngest hosts gained significantly more weight per gram of host tissue than $C$. campestris growing on plants of intermediate age, indicating that the differences in host size are not only an effect of host size at different ages.

\section{Resource acquisition on two hosts (experiment C)}

C. campestris growth was strongly affected by host species composition (Fig. 3a). At harvest, C. campestris accumulated the most $\mathrm{d}$. wt, carbon and nitrogen when growing on two $T$. resupinatum hosts and grew the smallest when parasitising two D. carota hosts (Fig. 3a). In the treatments with two different host species, $C$. campestris $\mathrm{d}$. wt and nitrogen content did not significantly differ, although on average, $C$. campestris was larger when its first host was $T$. resupinatum than when it was D. carota. The means lay between that of the two monocultures. The large differences between the two monocultures indicate that most resources in the two mixed-species treatments were also obtained from $T$. resupinatum hosts (Fig. 3a). The best tissue quality, measured as the $\mathrm{C}: \mathrm{N}$-ratio, was observed when $C$. campestris grew on two $T$. resupinatum hosts and the highest $\mathrm{C}: \mathrm{N}$-ratio occurred when $C$. campestris parasitised two Daucus plants (Fig. 3a).

Of the total $15 \mathrm{~N}$ label added to each labelled host, $7 \%$ to $32 \%$ was detected in the above ground biomass. $50 \%$ of this 
(a)
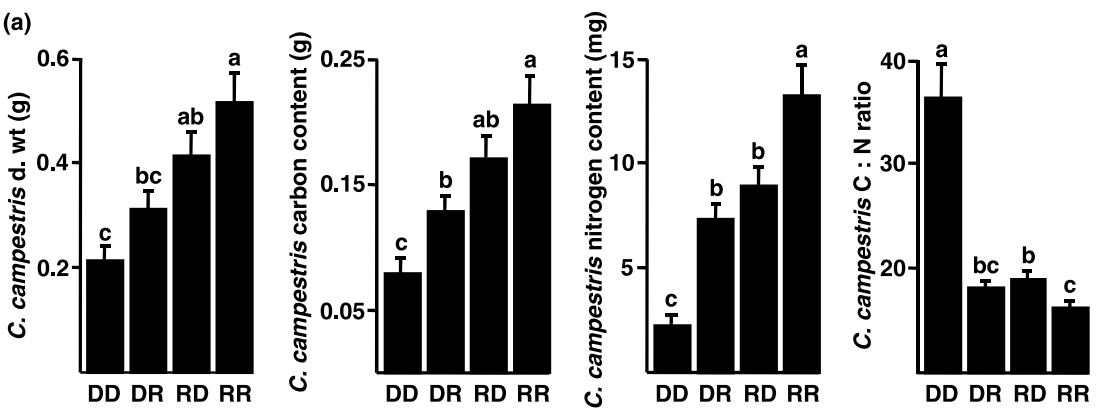

Host composition

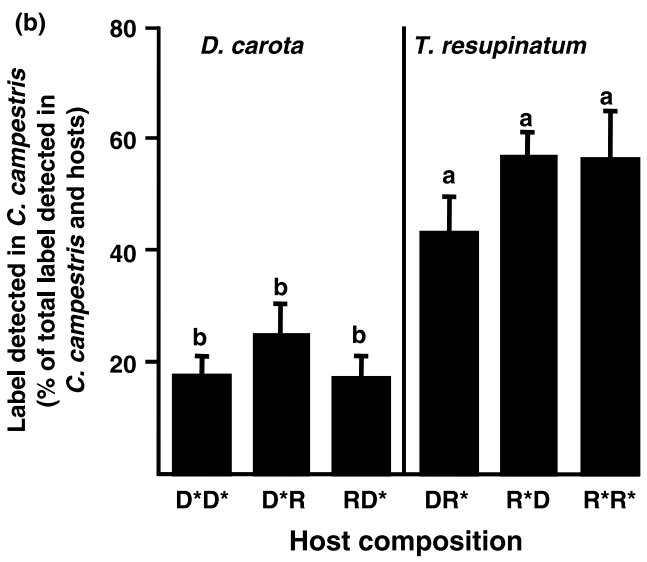

(a)

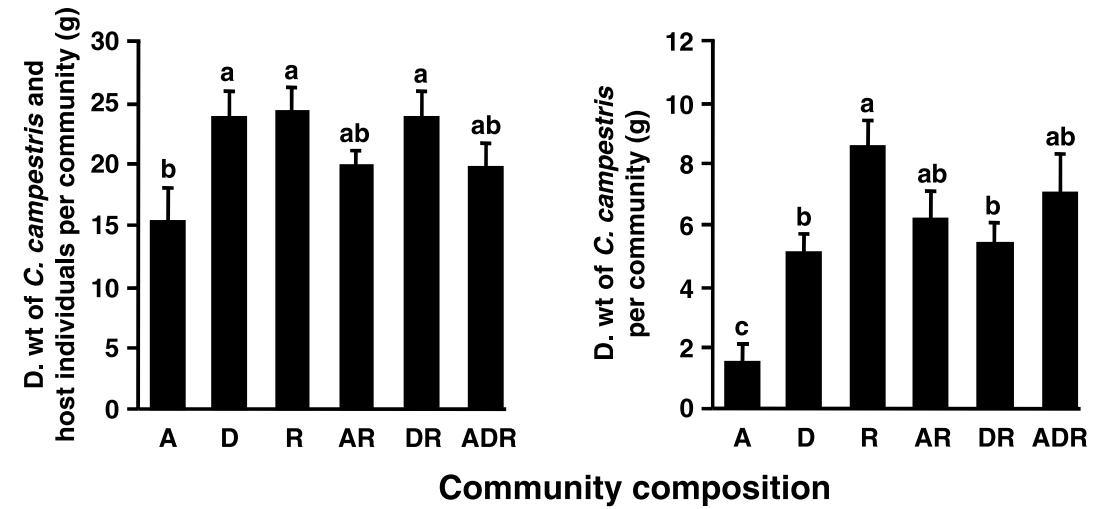

Fig. 3 (a) Mean Cuscuta campestris d. wt, carbon content, nitrogen content and $\mathrm{C}: \mathrm{N}$ ratio growing on four different host species combinations in experiment C. D represents Daucus carota and $\mathrm{R}$ represents Trifolium resupinatum. The first letter of each host combination represents the host on which parasitism was established and the second letter represents the second host that was parasitised. $F$-ratios from ANOVA were $F_{3.93}=9.76(P \leq 0.001), 10.52(P \leq 0.001)$, $24.38(P \leq 0.001)$ and $86.02(P \leq 0.001)$ for Cuscuta d. wt, nitrogen content and $C / N$ ratio, respectively. (b) Mean percentage of the total label detected (in Cuscuta and hosts) that occurred in $C$. campestris tissue, in the different label treatments DD, DR, RD and RR. An asterisk indicates which plants received label, in the two monocultures either the first or the second host received label. The F-ratio for the ANOVA across the six different labelling treatments was $F_{5,51}=10.64$ $(P \leq 0.001)$. Error bars represent $+1 \mathrm{SE}$. Different letters above bars indicate a significant difference at $P=0.05$, according to the LSD test.

Fig. 4 (a) Mean d. wt of all plants (Cuscuta campestris and hosts) and (b) d. wt of $C$. campestris per community in the different communities in experiment $D$. Letters $A, D$ and $\mathrm{R}$ represent the host species Trifolium alexandrinum, Daucus carota and $T$. resupinatum that were planted in the different communities. F-ratios for the ANOVAS were $F_{5,35}=2.76(P \leq 0.05)$ and $F_{5.35}=5.83$ $(P \leq 0.001)$, for $\mathrm{a}$ and $\mathrm{b}$, respectively. Error bars represent $+1 \mathrm{SE}$. Different letters above bars indicate a significant different at $P=0.05$, according to the LSD test.

detected label was taken up by $C$. campestris when the labelled host was T. resupinatum and about $20 \%$ when the labelled host was Daucus (Fig. 3b). In an ANCOva, where the number of parasite attachments on the labelled host was fitted as a covariate, the difference between the two host species was still significant (data not shown). This indicated that the quality of resources acquired through each attachment is clearly host dependent, that is an attachment formed on T. resupinatum gives more benefit to $C$. campestris than an attachment on D. carota.
C. campestris growth in communities of differing host composition (experiment D)

The total d. wt of the host communities (host shoots and C. campestris) differed significantly (Fig. 4a). The d. wt of C. campestris also differed between the treatments (Fig. 4b). In the monocultures, $C$. campestris grew significantly larger on T. resupinatum than on $D$. carota and $T$. alexandrinum. The biomass attained by $C$. campestris in the treatments with two or three host species lay between those of the monocultures 
New

Phytologist

Table 1 Mean rank sums of the order in which Cuscuta parasitised the hosts Trifolium alexandrinum (A), Daucus carota (D) and $T$. resupinatum $(R)$ in the different treatments (ADR, $A R$ and $D R$ )

\begin{tabular}{llll}
\hline Treatment & Host species & Mean rank sums & $\chi^{2}$ \\
\hline ADR & $\mathrm{A}$ & 28 & $14.27(P \leq 0.001)$ \\
& $\mathrm{D}$ & 33.2 & \\
& $\mathrm{R}$ & 16.1 & $14.31(P \leq 0.001)$ \\
$\mathrm{AR}$ & $\mathrm{A}$ & 55 & \\
& $\mathrm{R}$ & 34 & $13.38(P \leq 0.001)$ \\
$\mathrm{DR}$ & $\mathrm{D}$ & 36.3 & \\
& $\mathrm{R}$ & 20.5 & \\
\hline
\end{tabular}

The mean rank sums represent a measurement of how quickly a plant species was parasitised on average compared to other plant species. The rank sums were measured by assigning a number to each plant in the order in which they were parasitised, where the first plant to be parasitised was assigned the rank 1 and the second 2, etc. The Wilcoxon test was used to check whether the rank sums in each treatment deviated significantly from the no-foraging situation where the three hosts would be expected to have equal rank sums.

suggesting that there was no enhanced growth as the result of a mixed diet. Furthermore, there was no significant covariance between host and $C$. campestris weight for the treatment effects in an ANCOVA with $C$. campestris $\mathrm{d}$. wt as dependent variable, indicating that the treatment effect was not caused by size differences of the different hosts (data not shown).

Evidence was found for C. campestris foraging. In both two-host species treatments and also in the three-host species treatment, individuals of the most rewarding host species (T. resupinatum) were parasitised earlier than the other less rewarding host plants (Table 1). Qualitatively the same result was found when we repeated the analysis considering hosts as parasitised when $C$. campestris had formed one, two or more than three attachment sites on a hosts (data not shown). This indicates that when $C$. campestris has a choice of hosts offering different rewards, that it actively exploits the hosts of better quality faster. At harvest, the total number of attachments per microcosm was significantly correlated with the $\mathrm{d}$. wt of the C. campestris $(r=0.64 ; P \leq 0.001)$ and this measurement was therefore an estimator for $C$. campestris size and a measure of how much $C$. campestris invested into parasitising these host plants. When C. campestris parasitised the three monocultures, it formed significantly more attachments on $T$. resupinatum and $D$. carota than on the less rewarding host T. alexandrinum (Fig. 5; $F_{2,11}=12.95, P \leq 0.0001$ ). In both two-host species treatments, $C$. campestris invested significantly more into the most rewarding host $T$. resupinatum (Fig. 5, paired $t$-tests, $P \leq 0.0001$ and $P \leq 0.05$ for the AR and DR treatments, respectively). In the three species mixture, $C$. campestris parasitised all three host species differently (paired $t$-tests, $P \leq 0.01, P \leq 0.01$, and $P \leq 0.05$ for the comparisons $\mathrm{AD}, \mathrm{AR}$, and $\mathrm{DR}$, respectively); it formed more attachments on $T$. resupinatum than on $D$. carota, and invested the least in the least rewarding host $T$. alexandrinum. Comparison of the mean number of attachments of $C$. campestris on the same host species between treatments shows a tendency of the parasite to invest more into parasitising the less rewarding hosts in the monocultures than in the mixtures when more rewarding hosts are available. By contrast, C. campestris invested to a similar degree into the most rewarding host $T$. resupinatum irrespective of the presence or absence of hosts of a lower quality.

\section{Discussion}

\section{Host effects on Cuscuta}

In this study we show that three different host species significantly alter $C$. campestris growth for the size measurements stem length, number of attachment sites and $\mathrm{d}$. wt. These are
Fig. 5 The mean number of attachments made by Cuscuta campestris on the three different plant species in the monoculture treatments, and the treatments with two host species (AR and DR) and three host species (ADR) in experiment $D$. Different letters indicate a significant difference according to the LSD test (monocultures) and according to paired $t$-tests (two and three species mixtures). Error bars represent $+1 \mathrm{SE}$.

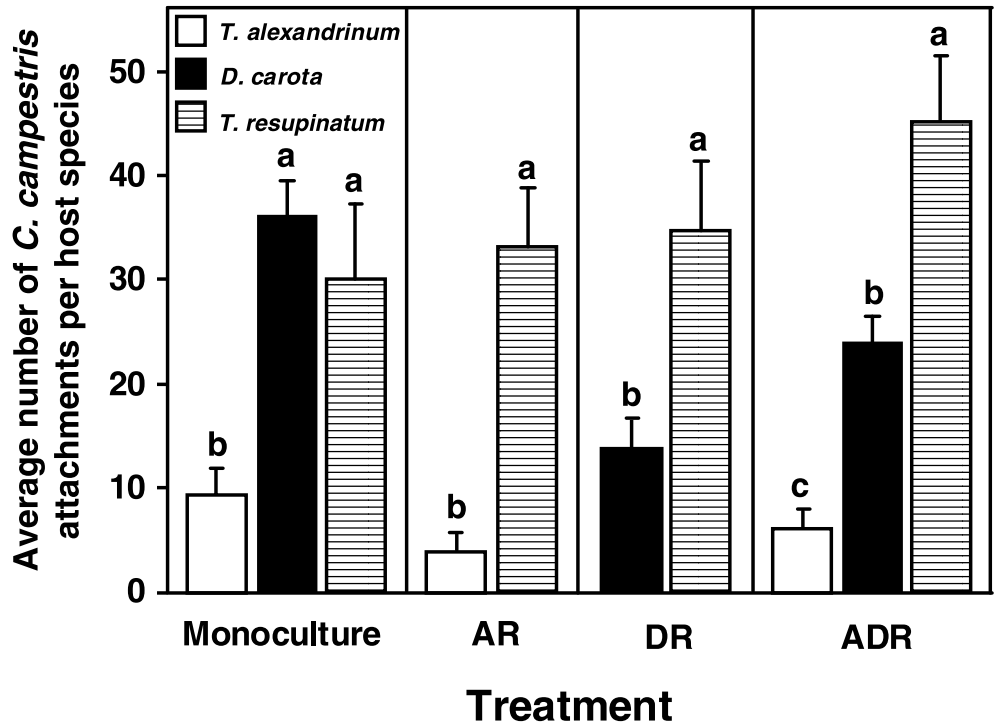


likely to be fitness related traits as $C$. campestris stem length and $\mathrm{d}$. wt are correlated with the weight of the reproductive tissue. Therefore, we have experimentally demonstrated resource heterogeneity among host species for $C$. campestris, an important prerequisite for the evolution of a foraging strategy. However, we also showed for $T$. resupinatum that within-host variation in age and size also alters $C$. campestris growth. This variation could contribute to the evolution of a foraging strategy that is not based on host species identity. In addition, other factors that we have not investigated, such as host nutrient status (Kelly, 1992) or salinity of the environment (Frost et al., 2003) could lead to inequality in the parasites reward from hosts of the same species. Furthermore, this indicates that a foraging strategy could also evolve in Cuscuta species that have narrow host ranges.

Another effect that we did not quantify in our study is that an increased parasite stem length is also likely to increase the area in which Cuscuta could search new potential host individuals. This would be an important component determining fitness of Cuscuta in a natural situation where a Cuscuta individual can parasitise many host individuals.

\section{Benefit of a mixed diet}

The host range of several Cuscuta species, including $C$. campestris, is very broad (Kuijt, 1969; Parker \& Riches, 1993). Several reasons could favour the maintenance of a wide host range: First there may be costs of distinguishing the different qualities of hosts and the costs of finding the next good host may be higher than parasitising a closer but less beneficial host (Sloggett \& Majerus, 2000). Second seedling survival could be increased because of a higher chance of germinating next to a host. Third a mixed diet is beneficial (Bernays \& Minkenberg, 1997; Marvier, 1998; Kelly \& Horning, 1999). Consequently, a host species specific foraging strategy is only likely to have evolved if the benefits would outweigh the costs for actively choosing hosts of only one species. In view of these possibilities, we have therefore experimentally examined whether a mixed diet increases $C$. campestris resource accumulation, in a mixed host community, where $C$. campestris could potentially enhance its growth by parasitising the most rewarding individuals. No evidence was obtained in either experiment $\mathrm{C}$ or $\mathrm{D}$ that a diet of mixed hosts rather than a single species enhanced growth beyond the expected growth on the monocultures. Experiment $\mathrm{C}$ showed that when $C$. campestris grew on different hosts it obtained most of its nitrogen from the more beneficial host $T$. resupinatum. In experiment $\mathrm{D}, \mathrm{d}$. wt accumulation of $C$. campestris in the mixed-species treatments were also in between the yields of the monocultures, indicating no direct benefit of a mixed diet. However, a mixed diet can still enhance parasite performance with other parasite or host species combinations (Kelly \& Horning, 1999), or have other benefits we did not measure, for example an altered performance of herbivores on the parasite (Marvier, 1998).

\section{Foraging by Cuscuta}

Experiment D differs from those previously performed on foraging in a mixed community in that our communities were standardised for spatial uniformity and the parasite actually had a choice in which plants it parasitised in the mixed-species treatments. Evidence for foraging was apparent in these mixed-species communities because $C$. campestris parasitised the most rewarding hosts fastest. The parasite also invested most into the most rewarding host, but a significant investment, in terms of number of attachment sites, was still made on the less rewarding hosts. It has been suggested that the evolution of a foraging strategy involves a preuptake recognition response to detect hosts of better quality and that coiling length is proportional to the parasites expected reward (Kelly, 1990; Kelly, 1992). In our experiments, there was a significant investment of $C$. campestris in hosts of lower quality. This does not exclude the possibility that $C$. campestris also exhibits a preuptake mechanism. However, here we argue that Cuscuta growth is dependent on all attachment sites formed during the entire growth phase and not only initial attachment sites. Since we have shown that attachments are quantitatively different on different host species the amount of resources received through the attachments could act as a mechanism for determining host quality and investment. Our data suggest that $C$. campestris invests in a host and determines resource quality by the amount of nutrients obtained and then allocates resources to investment in close proximity of this source, a pattern that resembles opportunistic foraging.

We conclude that our data present strong evidence for foraging in the parasitic plant $C$. campestris. For the combinations of parasite and host that we used, there was no evidence for a direct benefit of a mixed-species diet and, indeed, when $C$. campestris had the choice of parasitising hosts that offer different rewards, it parasitised and invested most on the most rewarding hosts. This was achieved through a faster and greater investment in number of attachment sites on the most rewarding hosts.

\section{Acknowledgements}

We thank Regula Bänninger, Sabine Flury, Claudia Heer, Kurt Ineichen, Susanna Meyer, Angela Schreiber and Claudia Schreiber for technical assistance, Jasmin Joshi for statistical advice, T. Lanini for collecting C. campestris seeds and two anonymous referees for their helpful comments on a previous version of this manuscript. We also thank Andres Wiemken and Thomas Boller for allowing this work to be conducted in the Botanical Institute, Basel. This work was supported by the Swiss National Science foundation (project 3100-046684.96) to which support is gratefully acknowledged.

\section{References}

Bernays EA, Minkenberg O. 1997. Insect herbivores: Different reasons for being a generalist. Ecology 78: 1157-1169. 
Beuret E. 1981. La cuscute champêtre (Cuscuta campestris Yunker), un parasite des cultures maraîchères valaisannes. Revue Suisse de Viticulture, d'Arboriculture et d'Horitculture 13: 141-148.

Charnov EL. 1976. Optimal foraging, marginal value theorem. Theoretical Population Biology 9: 129-136.

Christensen NM, Dorr I, Hansen M, van der Kooij TAW, Schulz A. 2003. Development of Cuscuta species on a partially incompatible host: induction of xylem transfer cells. Protoplasma 220: 131-142.

Dinelli G, Bonetti A, Tibiletti E. 1993. Photosynthetic and accessory pigments in Cuscuta-Campestris Yuncker and some hosts. Weed Research 33: $253-260$.

Evans JP, Cain ML. 1995. A spatially explicit test of foraging behaviour in a clonal plant. Ecology 76: 1147-1155.

Fischer M, Van Kleunen M. 2002. On the evolution of clonal plant life histories. Evolutionary Ecology 15: 565-582.

Frost A, Lopez-Gutierrez JC, Purrington CB. 2003. Fitness of Cuscuta salina (Convolvulaceae) parasitizing Beta vulgaris (Chenopodiaceae) grown under different salinity regimes. American Journal of Botany 90: 10321037.

Gibson DJ. 1988. The maintenance of plant and soil heterogeneity in dune grassland. Journal of Ecology 76: 497-508.

Hoagland DR, Arnon DI. 1950. The water-culture method for growing plants without soil. California Agricultural Experiment Station Circular 347.

Hutchings MJ, Wijesinghe DK. 1997. Patchy habitats, division of labour and growth dividends in clonal plants. Trends in Ecology and Evolution 12: 390-394.

Kelly CK. 1990. Plant foraging: a marginal value model and coiling response in Cuscuta subinclusa. Ecology 71: 1961-1925.

Kelly CK. 1992. Resource choice in Cuscuta europaea. Proceedings of the National Academy of Sciences, USA 89: 12194-12197.

Kelly CK, Horning K. 1999. Acquisition order and resource value in Cuscuta attenuata. Proceedings of the National Academy of Sciences, USA 96 13219-13222.

Koskela T, Puustinen S, Salonen V, Mutikainen P. 2002. Resistance and tolerance in a host plant-holoparasitic plant interaction: genetic variation and costs. Evolution 56: 899-908.
Koskela T, Salonen V, Mutikainen P. 2000. Local adaptation of a holoparasitic plant, Cuscuta europaea: variation among populations. Journal of Evolutionary Biology 13: 749-755.

Koskela T, Salonen V, Mutikainen P. 2001. Interaction of a host plant and its holoparasite: effects of previous selection by the parasite. Journal of Evolutionary Biology 14: 910-917.

Krebs JR, Erichsen JT, Webber MI, Charnov EL. 1977. Optimal prey selection in great tit (Parus major). Animal Behaviour 25: 30-38.

Kuijt J. 1969. The biology of parasitic flowering plants. Berkeley, CA, USA: University of California Press.

Mack NM, Harper JL. 1977. Interference in dune annuals: Spatial pattern and neighbourhood effects. Journal of Ecology 65: 345-363.

Marvier M. 1998. A mixed diet improves performance and herbivore resistance of a parasitic plant. Ecology 79: 1272-1280.

Milinski M, Heller R. 1978. Influence of a predator on optimal foraging behaviour of sticklebacks (Gasterosteus aculeatus L.). Nature 275: 642-644.

Parker C, Riches CR. 1993. Parasitic weeds of the world: biology and control. Wallingford, UK: CAB International.

Pennings SC, Callaway RM. 1996. Impact of a parasitic plant on the structure and dynamics of salt marsh vegetation. Ecology 77 : $1410-1419$.

Pennings SC, Callaway RM. 2002. Parasitic plants: parallels and contrasts with herbivores. Oecologia 131: 479-489.

Sloggett JJ, Majerus MEN. 2000. Habitat preferences and diet in the predatory Coccinellidae (Coleoptera): an evolutionary perspective. Biology Journal of the Linnean Society 70: 63-88.

Stuefer JF, During HJ, De Kroon H. 1994. High benefits of clonal integration in two stoloniferous species, in response to heterogeneous light environment. Journal of Ecology 82: 511-518.

Van Kleunen M, Stuefer JF. 1999. Quantifying the effects of reciprocal assimilate and water translocation in a clonal plant by the use of steamgirdling. Oikos 85: 135-145.

Venable DL, Pake CE, Caprio AC. 1993. Diversity and coexistence of sonoran desert winter annuals. Plant Species Biology 8: 207-216.

Zar JH. 1984. Biostatistical analysis, 2nd edn. Englewood Cliffs, NJ, USA: Perntice-Hall.

\section{About New Phytologist}

- New Phytologist is owned by a non-profit-making charitable trust dedicated to the promotion of plant science, facilitating projects from symposia to open access for our Tansley reviews. Complete information is available at www.newphytologist.org

- Regular papers, Letters, Research reviews, Rapid reports and Methods papers are encouraged. We are committed to rapid processing, from online submission through to publication 'as-ready' via OnlineEarly - average first decisions are just 5-6 weeks. Essential colour costs are free, and we provide 25 offprints as well as a PDF (i.e. an electronic version) for each article.

- For online summaries and ToC alerts, go to the website and click on 'Journal online'. You can take out a personal subscription to the journal for a fraction of the institutional price. Rates start at $£ 108$ in Europe/\$193 in the USA \& Canada for the online edition (click on 'Subscribe' at the website)

- If you have any questions, do get in touch with Central Office (newphytol@lancaster.ac.uk; tel +44 1524 592918) or, for a local contact in North America, the USA Office (newphytol@ornl.gov; tel 865576 5261) 